\title{
Social Acts and Social Systems: Community as Metaphor
}

\author{
Carol L. WinkelmanN \\ University of Michigan
}

\begin{abstract}
The community metaphor currently dominates much of the thinking in educational theory and pedagogy, especially in the field of composition and rhetoric. This study critiques the community metaphor through a tripartite analysis of student- and teacher-generated metaphors. Two textual levels of metaphors-in-use are considered: grammatical-semantic metaphors and lexical metaphors. A functional linguistic analysis demonstrates the thoroughly heteroglossic nature of language in classroom talk and text. This article contends it would be more useful for teachers to proceed from a collectivity metaphor as a way to capture the dynamic nature of language-inuse. Subsequently, both students and teachers can be more attentive to the ways in which they define themselves, through metaphor, as a group-in-process.
\end{abstract}

One humanistic way to conceptualize the classroom is that it is the location of a collaborative effort to build community. The teacher, recognizing that meaning is created, rather than instilled, allows a text to unfold. This text configures itself as a dialogic encounter between students and teachers: human beings who are reaching out toward common goals. In the language of the academy, these goals are articulated in terms of literacy skills: functional, higher order, and cultural. In the writing classroom, teachers understand these goals in terms of facilitating language acquisition. They recognize the need for students, especially at the university level, to acquire an agility with several types of academic language. So many of us steer class conversations around the demand on our students to "write across the curriculum" and, in keeping with the vision of the humanities, to do so critically. The notion of language community has, by and large, facilitated our task.

This article, however, concerns problematic aspects of the notion of language community as it is used in educational theory and practice. I will address some recent conceptions and criticisms of the notion of classroom as community, present a case study of one individual student within the framework of an analysis of metaphor and, finally, suggest an alternative approach to conceptualizing composition classrooms within the university setting.

I thank Patricia Stock for valuable comments on this research and $\mathrm{S}$. Jacqueline Anderson for editorial advice. I also benefitted from the critical remarks of the anonymous reviewers.

Correspondence and requests for reprints should be sent to Carol Winkelmann, Department of English Language and Literature, University of Michigan, Ann Arbor, MI 48109. 


\section{PART I: THE CLASSROOM AS COMMUNITY}

\section{An Institutional Paradox}

The notion of language community has permeated recent composition theory and, for many of us, the complementary notion of the classroom as community has transformed our pedagogical practices. To understand language as functional, learning as social, and classrooms as communities-in-the-making is preferable to our previous eclectic conceptions of learning environments. With these new understandings in the classroom, community becomes a metaphor by means of which language events and activities are understood. Students and teachers enact the formation of community within the classroom much like the disciplines have engaged in this historical process of community-building. At the same time, classroom participants look beyond their own community to those communities across the university in order to begin acquiring a facility with the diverse languages which constitute those disciplines. Yet, as generative as this metaphor has proven itself to be, it is not without difficulties.

Even for the thoughtful teacher, one problem with conceptualizing the classroom as a community-in-the-making is that, paradoxically, the text of the classroom is open to interpretation as a monolithic construction with the world view of the teacher-one who "speaks truthfully about what it means to be present" (Greene, 1978, p. 69) - at the center of the text. Subsequently, classroom participants - both teachers and students - often unknowingly engage in an "insideoutside" view of classroom life: Particular individuals are viewed as being positioned either inside or outside the dominant classroom ideology. More precisely, because students are viewed in terms of their relationship to the community itself, our conceptions of students risk becoming dichotomized. Students are often described by others in terms of commitment/lack of commitment, collaboration/refusal to engage in collaboration, or commonalities/deviations. Despite the good intentions of the teacher, the community metaphor itself guarantees that some students will be inevitably marginalized by interpreters of the classroom text: themselves, other students, the teacher. Plainly, there will always be some students who do not make their way to the center of the text where the "real" meanings apparently are being constructed. Variously designated, these students become signs - signs of failure-to be analyzed in the search for ever more harmonious, effective classrooms.

Humanistic perspectives, such as those undergirding the notion of the classroom as community, pivot on terms such as commitment and, finally, ethics. It is assumed that when communicative difficulties arise, individuals, acting intentionally, can change a community through ethical choices and commitment. Conflict is managed through negotiation, consensus, and the creation of a common language. This vision is beautifully articulated within broader parameters, for example, by Stock and Robinson (1990) and Greene (1978). 
Yet, problems with this vision frequently arise as teachers take up the community metaphor in the classroom. Certainly, those who use the language of ethics and commitment do not ignore the complexity of human situations in which, of course, ethical choices for some are unethical choices for others. As advocates attempt to structure classrooms around the metaphor of community, however, they often seem to underestimate the complexity of social systems and the relationship of individuals to systems. It seems the assumption frequently underlying the call to commitment is that the intentionality of individuals can be readily assimilated by a system. As Lemke (1984) noted, however, "Individuals cannot change social systems because individuals cannot interact with social systems: only other social systems may do so" (p. 47). Working with the community metaphor, teachers perhaps all too easily assume that one might pick and choose which communities to enter, learn the language of the communities, and then negotiate a way into them. This is to blind oneself to-among other issues-the facts of social mobility and opportunity. The call to create a common language, unless carefully considered, risks idealizing the ability of individuals to alter whole systems regulated by that which is conflictual in language and serves to maintain unnegotiable disjunctions among the social voices that constitute our diverse languages.

Heteroglossia is a term used by Bakhtin to designate this conflictual aspect of language. Analyzing the work of Dostoevsky, Bakhtin (1984) recognized the multiplicity of independent voices orchestrated by the Russian novelist. These voices are the specch of the various characters in Dostoevsky's novels. Yet, the speech of any individual character is also filled with the words of others. This is because no one ever addresses a given topic for the first time in any utterance. The words of others regarding the topic under consideration are assimulated, reworked, and reaccentuated by the individual (cf. 1986). Voices layer upon other voices.

Far from merging with the voice of the novelist or one another, all these voices remain distinct, that is, they are dialogic: neither monologic nor dialectic. Dostoevsky's artistic genius, contended Bakhtin (1984), lay in the orchestration of the voices, the distribution of a conglomerate of contradictory voices through which a central theme was passed.

Although recognizing this living mix of "varied and opposed languages" in the language of the novel, Bakhtin did not limit his finding to this genre. The irrevocable and conflictual "multivariedness" of the discourse of the novel, he realized, extended to all language. Heteroglossia, conflictual meaning, is present in all discourse and insures the dynamism of living language (Bakhtin, 1981). With regard to the utterance, Bakhtin (1986) contended: "Various viewpoints, world views, and trends cross, converge, and diverge in it" (p. 93). Contradictory accents clash even within words as they are formulated in different contexts: The meanings of words are changed as they are transferred from one voice to 
another. The clashing of meaning within the word drives the language event forward as speakers and listeners, readers and writers, search for understandings, as they participate in the creation of meaning.

Thus, for Bakhtin, a unitary language is simply a construct. Poets (and politicians perhaps) may seek to monologize the word. Yet, it is diversity, conflict, and change that characterizes authentic language. And, whereas ethics and responsibility were key ideas to Bakhtin (1984), he understood these ideas within the framework of irrevocably conflictual nature - the heteroglossic nature-of all discourse.

In this article, I consider heteroglossia as it surfaces in metaphor. Taking my lead from Bakhtin, I search for contradictory accents appearing in word use; that is, I look at variance in the lexis chosen by students to define community. I also look at heteroglossia as it appears at the grammatical-semantic level of language use by examining variance in the patterning of words at clause level. For teacher researchers, the metaphorical language chosen by students can function as a window to classroom life as experienced by students: a world thoroughly imbued with heteroglossia.

Viewing the classroom only through the lens of the unifying community metaphor, teachers and students often seem to neglect the heteroglossic nature of language. Conflict is treated as a malfunction or disruption: a rend in the community fabric which must be patched or mended.

\section{Mending the Metaphor: Resistance}

Responses to the concept of the classroom as a language community have been formulated as part of a wider response to the concept of discourse communities in general. Recognizing that conflict frequently surfaces in communities-and that this is perhaps even desirable-some theorists speak of conflict and change in the typical meaning formations of discourse communities in terms of resistance. Such theorists value resistance as manifested in the classroom for its explanatory and dynamic capacities.

However, a simple recuperation of the term resistance-arguments engaged in by Marxists in response to the language of humanism-will not do. Teachers are simply dealing with the underside of the language of community and conventionality in terms of degrees of alienation from social groups (e.g. Giroux, 1981, 1988; Giroux \& Aronowitz, 1985; Willis, 1977). Although Marxist educational theorists frequently treat both micro and macro levels of analysis, they label students who engage in disruptive behavior as resisters, marginalized students. In effect, students remain the focus of an analysis of localized systems from which they are somehow detached.

Marxist educational theory has provided a useful method of analysis for thoughtful teacher researchers of the classroom. It could be made even more so if apparently marginalized students were reconceived as clearly central to the overall text of the classroom. In addition, as it is applied in the classroom, Marxist 
educational theory is only critical to the degree that resistant behavior is recognized as easily neutralized by the dominating ideological systems functioning in group activity. This phenomenon is known to semioticians as dynamic metastability: the invariant state of a system due to the presence of sanctioned subsystems which function to contain and sometimes exhaust chaos within larger systems (see Lemke, 1984). The point is that students who engage in apparently resistant behavior are fundamental to a description of the communicative system of a classroom (Winkelmann, 1990). The labels typically applied to such students tend to mask global patterns of group interaction.

Attempting to mend the community metaphor with the notion of resistance, as I myself have tried to do in the classroom, is not the answer. It is not even a matter of reserving the term community for a specific and local group (cf. Harris, 1989); rather, it is a matter of coming to terms with the nature of communication: "intentionality," if you will, but primarily as it plays itself out in a system of signs.

The reality of heteroglossia in everyday language use is a complexity which calls for more than mending strategies.

\section{Rethinking the Metaphor: Conflict in Social Systems}

Instead of conceptualizing the diverse individuals who gather together in a classroom from the framework of a community metaphor, I propose that it is more generative for teacher researchers to analyze the classroom as a semiotic system in which the students themselves become signs in a multitiered sign system (cf. Zaliznjak, Ivanov, \& Toporov, 1988). I suggest that the classroom is more akin to a collectivity wherein individuals, who are more aptly conceptualized in terms of diverse social voices that constitute their language, are engaged in various semiotic tasks, only some of which might be held in common. The collectivity is distinguishable by the dynamic channels of communication it operationalizes: not all of which are intersected by the teacher and not all of which are linguistic. Networks are formed which function multipurposively within the classroom, but which also include critical points of contact outside the classroom. The networkings are traversed only in as much as the channels remain functional; thus, it is patterns of significant signals in the classroom that determine the nature of the interpretation of the experience of the classroom for any participant.

In order to demonstrate why such a conceptualization might be better suited for teacher researchers who proceed from a social theory of language, and who seek to keep theory and practice consistent, I will focus on one type of signmetaphor-realized in the interactive linguistic events of Katherine, a member of a writing course I taught collaboratively at the University of Michigan.

\section{The Context: A Course in Language and Community}

The reconsideration of the metaphor of community is more than a simple quibble about terminology. It has to do with ways of conceptualizing social actions in 
relation to entire systems of social activity. As Lemke (1984) has aptly noted, typical social analysis constructs continuities whereas discontinuities are made to seem peripheral. Local patterns of interaction tend to mask global patterns. The thoroughly heteroglossic nature of language frequently is ignored. Conflict is viewed negatively, that is, as the simple converse of acceptance of standards and norms.

The spoken and written texts of Katherine leave her actions open to such misconstrual. The situation in which Katherine found herself was an intensive writing course for transfer students based upon a rhetorical approach to the teaching of writing. Entitled "Language and Community: Writing and Resistance," the course was collaboratively taught by Cathy Fleischer, Patricia Stock, and myself in the fall of 1988. Student writing, the subject matter of the course, was discussed against a background of the typical patterns of language use in discourse communities across the university. During one intense phase of the course, students wrote three papers on one self-selected topic from three different perspectives or genres. These papers were submitted both to peer groups and to the class at large for discussion. Evaluation of student texts was a collaborative endeavor: Standards for scholarship were arrived at communally and grades were determined by small groups composed of at least one teacher and several students who negotiated a letter grade. Student writers were invited to revise and to resubmit texts at any point during the course.

In addition to these activities, articles written by a wide variety of scholars from various discourse communities were also discussed. The focus was on the diverse conventions used to construct knowledge and to present research. In small groups, students with shared academic interests interviewed professors and presented their findings to the class at large. They collaboratively wrote a text about this experience and distributed it to interested members of the class. At one point during the course, students participated in a panel discussion with professors trom across the university who spoke about the diverse conventions in their fields for the construction of texts. Students subsequently wrote reaction papers in regard to what they had learned about academic writing from the panelists.

Because the teachers had already begun to suspect some of the inherent problems with the community metaphor, the course was designed to probe the necessary tension between conventions and resistance to conventions in academic writing and speaking. Students were invited to think of speaking and writing as social action and, thus, as possible locations of attempts by individuals to claim genuine authorship of texts (cf. Geertz, 1988) through critical choices in relation to preexistent discursive formations. The risks and consequences of such critical actions were probed. At the same time, the metaphor of the classroom as a community in formation still governed activities such as whole-group conversations, peer-group work, and teacher- and peer-grading of student writing. The 
teachers believed that a common language could be formed to arrive at shared understandings within the classroom.

One student, in particular, began to challenge my thinking about this common language and the community metaphor. Katherine, a 19-year-old woman of Iranian-Macedonian descent, was a member of a peer group that met regularly throughout the semester as sympathetic readers for writing drafts. She was a quiet woman who chose to write a series of papers about Macedonian life in the genre of historical narration. Her sympathetic readers were Alaine and Hanna, two women who did not define themselves, as Katherine did, in terms of ethnicity. In an interview several weeks following the course, Katherine described "commonalities" within her peer group:

Text 1

K: I think it's just the kind of person I am that's different than the kind of people they are. I'm that kind of person because of the kinds of things I value and I don't know. Just everything about me I guess was different. Like what exactly? Just everything, everything different.

C: So you perceive yourself as having nothing in common with Alaine and Hanna?

K: No.

$\mathrm{C}$ : If you had to think of any one thing that you did have in common?

$\mathrm{K}$ : We were girls I guess. What else? That was it.

So much for the formation of community. In the language of community, Katherine was apparently a resister. Generally quiet, frequently hostile, Katherine could not negotiate a productive relationship with critical, engaged Alaine and smiling, talkative Hanna. In whole-group activities, she had difficulties as well. She saw herself, and was seen by the teachers and other students, as marginalized. Even more, she defined herself as an outcast. For the teacher researchers, Katherine became a sign in the system: a sign of failure to be analyzed in the hopes of understanding and reshaping the dynamics of classroom life.

\section{PART II: ANALYSIS OF METAPHOR AS MULTILEVEL SIGN IN THE SYSTEM}

A textual analysis of Katherine's use of metaphor is a way to isolate one strand among a web of signifying activities in which Katherine engaged. I consider metaphor on two textual levels in a tripartite analysis of classroom meaningmaking. First, I consider the grammatical-semantic structures manifested in Katherine's texts. Halliday (1985) offered a method of microanalysis which presupposes the nondeviant existence of grammatical metaphor in individual 
language use. In particular, I focus on Halliday's ideational and interpersonal functions of language as they are evidenced in Katherine's texts.

Second, I consider metaphor in terms of lexical, or lexicosemantic processes in Katherine's texts. At this stage of the analysis, I appropriate some of the terminology and ideas of linguist Jay Lemke. Lemke does not work specifically with metaphor; yet, he provides a way to link the microanalysis to an intermediate level of analysis by viewing rhetorical devices as phenomena of intertextuality: ways in which individual instances of language use relate to typical discursive formations (Lemke, 1983).

Third, I reconsider the lexical level of meaning-making as it is manifested in communal texts; that is, I reconsider intertextuality as it surfaces in wider classroom activity. At this point, I broaden my focus to consider briefly metaphors that take shape outside the teachers' metaphor of community. Some social scientists (Ortony, 1979; Petrie, 1979; Srivastva \& Barrett, 1988) see the formation of collective metaphors as part of the normal process of group dynamics; that is, their work suggests the possibility of an intermediate to macroanalysis of metaphor.

In this discussion, 1 follow Halliday's view that metaphor, either grammatical or lexical, can be defined as variation in the use of words. It is verbal transference: In the expression of meaning, the language user may select along a continuum from literal (or congruent) to metaphorical forms of language. Metaphor is transferred meaning; that is, "different from that which is in some sense typical or unmarked" (Halliday, 1985, pp. 320-321). Transference may also be thought of as the movement of information from a primary clause to another clause: a strategy used to alter the semantic impact of information. At the same time, this use of metaphor is nondeviant: It represents the normal functioning of words in context as a language user selects metaphorical language for specific semantic content. Like all language, metaphor is ultimately a matter of choice and, thus, the analysis of metaphor can reveal significant signifying patterns in a social system. In this analysis, my specific focus will be on how metaphor functions systemically, that is, as part of a larger linguistic environment.

\section{Grammatical-Semantic Structures}

In the following episode, Katherine interprets Hanna and Alaine's reaction to the papers she wrote during the semester. This episode coalesces themes which recurred many times in the conversations Katherine and I had following the course.

1 well

2 they

3 it was hard for

4 I know 
5 it was probably really hard for them

6 because like

7 they could pick out like plain to see kinds of things

8 but

9 like you know

10 make your sentences more correct of this or that

11 rephrase this

12 or

13 you'te in the third person or in the first

14 so

15 to them

16 that kind of stuff stuck out

\section{Ideational Metaphors}

Functional linguistics offers a method, as noted above, of analyzing grammatical metaphor as it appears in Katherine's oral text. According to Halliday's (1985) theory, two types of grammatical metaphor may appear in the clause: ideational metaphors and interpersonal metaphors. Ideational metaphors, like interpersonal metaphors, are modes of expression that depart from typical ways of saying things in a speech community, that is, the forms range from unmarked to marked forms of language. Interpretation of ideational metaphors involves the analysis of the functions of language in terms of ideas and information. It involves the analysis of speaker configuration of participants, processes, and circumstances, that is, in tcrms of transitivity. As she makes selections from the system of transitivity, Katherine has a choice. Because the options are not exactly synonymous, however, her selections are meaningful. Metaphors of transitivity can reveal something about how Katherine understands the community.

Readers unfamiliar with Halliday's work on transitivity will discover that the terminology used to describe the functions of words in discourse is somewhat self-descriptive. For example, a participant in a clause (traditional subject or not) may be an ACTOR, BEHAVER, SENSER, SAYER, and so forth. A verb process in a clause may include types such as MATERIAL, BEHAVIORAL, MENTAL, VERBAL, and so forth. The functions work complementarily: Participants engage in complementary processes. For example, a SENSER would be engaged in MENTAL processes. To illustrate, in the sentence, "I don't like it," the grammar designates "I" as SENSER and "like" as a MENTAL process.

Using this framework, I will focus especially on lines 7 and 16, which include marked grammatical metaphors. In them, Katherine is shaping language in a way that departs from the anticipated forms.

In line 7, Katherine represents Alaine and Hanna as ACTOR (they) involved in a MATERIAL PROCESS (could pick out) directed toward a QUALIFIED (plain to see) GOAL (kinds of things). This selection is dynamically meaningful in relation to the frame which precedes line 16 and also in relation to the selections following line 16 , as will be seen shortly. Katherine hegins this episode with a framing 
device (line 1: well) which, as a continuative, posits the whole episode as a considered commentary. She posits Alaine and Hanna as ACTOR (they) in line 2. Then she quickly qualifies this (lines 3-6) through a series of selections: She places her own work as-or integral to-a situation subject (line 5: it) and she positions Alaine and Hanna in an intensive relationship with the situation in the predicational material at the clausal end (was hard for them), that is, in an unmarked position. In line 4 , Katherine configures her own role as a SENSER in a MENTAL PROCESS of COGNITION ( $I$ know) in critical difference to her peers" subsequent role as ACTOR in line 7.

The first half of this episode, then, is a wavelike movement in which Katherine sees both a cause-effect relationship between her peers' response to her work and her own role as different from their role in the situation. Katherine senses; her peers act. Yet, their role is limited by the situation itself: It was probably hard for them, as she says in another episode, because they were "amateurs" in the process of critical response to writing. This wavelike movement manifests an ethical dimension: Both a sympathy on Katherine's part for her peers and a recognition of her own dignity vis-a-vis the context of situation: an interview with the teacher. Thus, in line 8 (i.e., but) an adversative extension of her peer's limited role-as configured in the gearing together of the grammatical metaphor of line 7 (i.e., could pick out) and the contrast it forms with line 4 -is aborted. Instead, Katherine elaborates by a series of exemplifications, that is, she projects, by direct quotation, exemplary responses of her peers: make your sentences more correct and so forth.

In line 16, Katherine offers a new grammatical metaphor (i.e., stuck out). Now, however, the characteristics of her written work (that kind of stuff) take over the role of ACTOR in a MATERIAL PROCESS (stuck out). This metaphoric configuration was chosen instead of a congruent possibility, for example, they noticed certain sentences. Had Katherine selected this second option, she would have portrayed her peers as she had herself: as SENSER involved in a MENTAL PROCESS. The important thing to realize is this: Through grammatical metaphor, Katherine finally allows both herself and her peers a kind of dignity by making her own written work the "active" culprit. In terms of the ideational function of language, then, this whole episode is exemplary of her own indecision about the exact reasons why her peer group failed and exemplary of her own sympathy, tactfulness, and understanding. These qualities are made functional only in the teacher-student relationship of the interview.

\section{Interpersonal Metaphor}

This reading of ideational metaphor in Katherine's text is supported by a complementary analysis of the interpersonal function of language of the text. Grammatical metaphor, Halliday (1985) noted, also operates on the level of language as exchange between interlocutors. The interpersonal function expresses social and personal relations and, gearing together with the ideational function, drives forward the speech event. In particular, the interpersonal function reveals signifi- 
cant information through selections in modality and mood. By carefully considering Katherine's selections, for example, something can be learned about the way she sees her relationship with her peer group.

In this section, I look at Katherine's choices of metaphors of modality. Following Halliday (1985), I view metaphors of modality as the transference of information regarding degrees of probability from a congruent realization to a less congruent realization. The language user has a choice about how and where in a clause complex to codify information about probability. Probability can be expressed as a subjective or objective category and it can be located in a primary clause or projected into a different clause for thematic value. The choices are meaningful.

I also look at Katherine's choices of metaphors of mood. Mood is codified through selections of basic speech functions: offers, statements, questions, commands. In the analysis, it is shown how Katherine interprets power relations within her peer group and in the teacher-student conference by focussing on the speech functions she selects to represent reality. Once again, there are choices to be made. Katherine makes use of metaphorical transference as she moves from the representation of mood in her peer group to the representation of mood in the subsequent teacher-student conference.

Of interest now are lines 4 and 5 , and lines 10 and 11 . In line 4 (I know), Katherine offers modality characterized by subjectivity through which she presents, in line 5 (it was probably really hard for them), modality characterized by objectivity. That is, she allows her own subjectivity to carry the responsibility of the interpretation of her peers as, in all probability, objective. More specifically, these two lines are indicative, but with modalization which plays between strong probability (I know) and certainty (it was). This is a metaphorical transfer of their "objectivity" (i.e., as she construes it) to her own subjectivity. The critical entailing modality, then, is dressed up as a proposition that, posited as a polarity (i.e., capable of being responded to with a yes or a no), can be rejected by the listener: She takes responsibility of the fact as truth on herself ( $I$ know $=I$ believe). She mediates her peers' objectivity through her own subjectivity; thus, one can refute them only by way of refuting Katherine herself.

However, in lines 10 and 11 , the initial elaboration of Alaine and Hanna's response to her work, Katherine switches from proposition to a series of imperative proposals that her peers make to her. According to her interpretation, her peers place her into an interlocutor role in which a high degree of obligation is required: line 10 (Make!), line 11 (Rephrase!). So now their thetorical role is a power role constituted by the formation of language in the function of order, which shifts, in line 13, to an informative function (you' re in the third person or in the first). Katherine, perhaps unwittingly, has made a subtle point about how power is signaled in interpersonal relationships. She makes the point by allowing for a sharp contrast between her own choices and her peer group's choices on the mood and modality level of language.

This analysis of the wavelike configuring and situating of ideational and 
interpersonal grammatical metaphor suggests a rather turbulent world view for Katherine. She seems to view herself as involved in a language skirmish of sorts in which she allows herself to function sympathetically with the teacher as interlocutor. Her peers are constrained by their level of expertise; however, unlike Katherine herself, they are interpreted by Katherine as unwilling to take on subjective responsibility for the situation. Instead, they function in power plays with her, ordering her into a position of dependence and culpability, which she is only willing to assume to herself-here at least - in private and on reflection.

The signs she makes functional, then, are both temporally and spatially diverse. In Texts 3 and 4, Katherine reveals how she received the orders of her peer group after a period of time in which she actually revised her texts on the basis of peer-group commentary.

\section{Text 3}

1 I didn't want their criticisms

2 I didn't want their help

3 I didn't take

4 I didn't take their criticisms

\section{Text 4}

I I was always interrupting them

2 I liked to interrupt

3 because

4 they wouldn't talk to

5 I kept interrupting them on purpose

6 because

7 I wanted to find out about my paper

8 they would breathe heavy

9 because

10 I kept interrupting them

11 I think I was making them mad

The differences among the dynamics outlined in Texts 2,3 , and 4 are obvious. The sympathetic role Katherine assumes for herself in Text 2 vanishes in Texts 3 and 4 . This does not mean that Katherine construed a false world for the benefit of the interviewer teacher. Indeed, Katherine's interpretation of peer-group dynamics may well have surprised even Alaine and Hanna. In the teacher-student conference, however, Hanna confirmed the failure of the group to coalesce. According to Hanna, the failure was due largely to Katherine's personality and childlike writing by which she meant: characterized by simplicity and mechanical errors. Nonetheless, the differences among Texts 2, 3, and 4 clearly demonstrate that Katherine-as-sympathetic-interlocutor was not functional within the peer group. In view of her interpretation of Alaine and Hanna's presentations-ofself in both Texts 2 and 3, this is not surprising. The peer group in the role as 
sympathetic readers was apparently not functional either. Katherine's high hopes for the efficacy of the peer group, revealed over and over in both the interviews and her journal entries, were dashed. Finally, she stopped hoping for the sympathetic signals from Alaine and Hanna that she herself offered on this occasion to the interviewer teacher. The signals she did perceive as functional were signals of the peer group as conflictive. Heteroglossia permeates the language of the peer group. Conflictual, contradictory accents infuse the grammatical-semantic level of Katherine's texts as she interprets peer-group activity. Katherine sums it up without microscopic textual analysis. In her words, "just everything, everything different. Everything too different."

\section{Intertextuality: Aligning and Colliding Discourse}

If Katherine's signifying difficulties had been confined to Alaine and Hanna, the solution would have been obvious. Katherine puts it simply: I guess I should have changed [peer] groups. However, an intermediate-level analysis of metaphor-as it configured itself in sets of relations between Katherine and the class as functioning under an imposed metaphor of community-reveals new complexities. The force of Katherine's selection of metaphoric language in lines 7 and 16 in Text 2 (i.e., pick out and stuck out) becomes meaningful only in relationship to the surrounding grammatico-lexical choices; yet, these choices are embedded within, and linked to, a larger system of semiotic choices.

\section{Lexical Metaphor}

In the previous discussion, meaning was considered as it is deployed through choices on the grammatical level. Lexicosemantic choices within the clause can also be examined. It is within the clause that the two choices intersect. The focus in this discussion, then, is lexical metaphor as it is distilled from two data sources: 45 pages of transcripts of spoken language between Katherine and me in which she explicitly and implicitly reveals her attitudes about community, and other teacher and student texts such as the class log, a public document in which participants took turns recounting and interpreting the events of a class session. Reviewing these transcripts and written texts, I searched for evidence of participant attitudes and beliefs about community. I grouped this evidence, in the form of more and less metaphoric language on the level of lexis, into thematic categories and attempted to translate the categories into a set of conditions. These conditions define how Katherine and other class participants viewed rules for activity in this particular community.

As noted above, my working notion of metaphor in this discussion follows Halliday (1985) in recognizing metaphoric language as frequently involving lexicosemantic variation. In expressing meaning, a language user may select from a range of words on a continuum of sorts from literal to something that is not, from congruent to less congruent. Sometimes grammatical processes are not involved; sometimes they are. For example, in characterizing a member of her 
peer group, Katherine says, "she likes to play the leader." A more congruent option would have been, "she is the leader." Katherine chooses to use a metaphor mapped onto a verbal process. By using metaphorical language, she makes an important statement about role playing in the community. Thus, it will be assumed that Katherine selects certain characteristics over other possibilities in metaphoric language and that the possibility of selection makes the use of metaphor an ideological process (Eco, 1984).

At other times, Katherine uses less metaphoric, often highly explicit language, to define community, that is, she selects basically congruent forms of language use. 1 present a range of evidence: more and less congruent realizations. I do not identify classical metaphoric relationships such as metonymy or synecdoche; rather, I will subsume all figures of speech under the general term of metaphor. Also, I move away from a Hallidayan analysis by focussing on lexical choice only, and disregarding a study of concurrent grammatical processes when grammatical processes have been affected. Once again, however, my focus is on the deployment of metaphor and the systematic relations that obtain between individual and communal formations of use

The sources previously described--the transcripts and other communal texts-- form a text in which more and less metaphorical language on the level of lexis represents a set of nodes between which heteroglossic (conflictual) relations obtain. Thus, the text reveals the intertextuality of language between occasions of use inside and outside the communal text. It also reveals the divergent relations between individual instantiations of language use and the typical formations of a group.

In our conversations, Katherine provided one set of nodes in the system of heteroglossic relations. Recurrent selected characteristics can be listed as a set of more or less metaphorical or abstract conditions for the formation and sustenance of community, according to Katherine. The act of "thematicizing" lexical metaphors into abstract conditions is an act of interpretation that extends, of course, above the clause. Yet, it is a move that allows one to view linguistic activity, separated by time, as a cumulative text. It allows the relationship of different instances of language-in-use to be seen. A particular utterance finds its meaning by its relationship to this cumulative text. Nevertheless, the abstract conditions do represent an act of interpretation. Thus, to demonstrate how I distilled the various lexical metaphors of Katherine's texts into one (sometimes more, sometimes less) abstract condition, I offer some examples of her actual locutions that pertain to her peer group and other participants in the course. I also provide a brief explanatory paragraph under each condition.

1. Community is not dramaturgical.

a. "Alaine likes to play the leader"

b. "I thought she was just a phony /always/you know/ when she would come to class and stuff she was really chipper and it was kind of sickening" 
Comment: Katherine sees members of community as overly engaged in role playing. She views this as less than sincere behavior. She sees a distinction, for example, between cheerfulness and dramatizing cheerfulness for social effect. In genuine community, participants are honest.

2. Community is not excavation: vertical.

a. "I have to dig and push for ... / /wcll/ what about this?"

b. "she'd [Alaine] be interested in impressing people/ impressing them with showing them that she is strong"

Comment: As demonstrated in Condition 1, Katherine is concerned about the effect of role playing. Here she metaphorizes cause and effect spatially, in terms of verticality. Because Alaine forces a social role (down) on others, Katherine is forced to dig, to work, for honest, full commentary on her writing, the topic of concern in $2 \mathrm{a}$. For Katherine, real community members ought to level with one another.

3. Community is a measurable commodity of which less is better.

a. "people fighting to talk /enough talking/ we talk too much"

b. "she listened to the whole junk"

c. "I didn't have anything she could use"

Comment: Clearly, Katherine sees this community as viewing talk as a commodity. Talk is a thing to be used in the maintenance of roles. If community abuses talk, then-for Katherine-less talk is preferable.

4. Community is linear: horizontal.

a. "I don't go out of my way to make friends"

b. "why should she go out of her way if she's not going to get equal attention?" Comment: Katherine once again metaphorizes spatially. In this community, participants are forced to change social strategies in order to find social or intellectual satisfaction. For Katherine, no detours should be necessary. Real community is straightforward, on the level.

5. Community is task oriented.

"half the time I didn't even care about their personal lives / I didn't want to talk about her escapades/ we were supposed to read papers/ we were supposed to talk about "Apropos" [a student text] /might as well/ that's what we were there for / you guys would think I wasn't doing my work"

Comment: Clearly, Katherine prioritizes the intellectual work of the community. In this community, she sees social activity as receiving preference over intellectual activity.

6. Community sits; it does not stand.

a. "we'd sit together and look at it [she and her sister] whereas they [Alaine and Hanna] would take it home and just read it"

b. "I wasn't really part of it /I was the door /the wall/ I just stood there while they talked/ I couldn't really leave because you'd think I wasn't doing my peer group"

Comment: For Katherine, community participants should be comfortable with one another. Because she interprets this community as not leveling with one another, she is not allowed to relax and enjoy the intellectual work of the community [cf. Conditions 2 and 4: Community is horizontal, not vertical] 
Katherine's utterances have a pathos obvious to any sensitive interpreter of her text. The genuine force of metaphor, however, is only construable from its position in a typical discursive formation. I offer a list of ALTERNATE CONDITIONS drawn from the texts of other students and teachers to demonstrate, condition by condition, the heteroglossic nature of the classroom language. Some conditions suggested by the other participants are in alignment with Katherine's conditions; some are not.

1. Community is dramaturgical.

a. From a student log: "Eliot then proceeded to steal the show and tell us about the way things are at BU. I think Eliot is really on top of things and has a lot going for him. Reminds me of me. Ha! Ha!"

b. From a teacher log: "We gathered. The visiting experts took their positions earned with authority at the front of the room."

c. From a student log: "It was a nice luesday and everybody was in class, one person was late, we won't mention that person's name, and class started out as usual with the prehand discussion on something out of the ordinary. I didn't get in on the discussion because I arrived when it was just ending, so I can't tell you what the topic was."

Comment: Contrary to Katherine's view, these participants enjoy role playing. Eliot and the professors are on stage. The "out of the ordinary" is ordinary in this community: something for which to strive.

2. Community is excavation: vertical

a. From a teacher log: "I am delighted when Eliot throws up Foucault to us all. I delight in the writings of Foucault . . . because they are so damned difficult to penetrate, and because understanding them has been such a delight for me once I have done it"

b. From a student log: "Carol opened up class telling us that many people wrote in their journals about article \# 17: what did you do in English today ... By the way, don't forget your switchblades Tuesday. Ha! Ha!"

Comment: Like Katherine, class participants metaphorize class activity spatially. vertically. Unlike Katherine, they regard the activities with levity. Most class activity is "up"; still, difficulty (e.g, , reading Foucault) is "down." Heteroglossia is thick here.

3. Community is a measurable commodity of which more is better.

a. From a foregrounded teacher log: "she [one of the other teachers] said that one of the points of us all being there was for us all to be participants in the conversation . . . I was a bit worried at first because I thought that no one was going to ask questions... I was pleased when questions started coming forth."

b. From a student log: "Unfortunately, at the time of this discussion I had not yet seen the panel discussion, but I did get much out of the group meeting"

Comment: Like Katherine, some class participants see talk as commodity. Unlike Katherine, they equate it with real community. The more, the better.

4. Community is linear: horizontal.

a. Initial class consensus on a standard for writing in the community: "Get to the point strategically and with style" 
b. From a student log: "Cathy and I thought that there will be rewards and failures, but in the long run you will succeed because you grow and learn with each attempt"

Comment: Class participants, like Katherine, metaphorize spatially. Contrary to her view, however, they see strategizing to move from "point $A$ " to "point B" as integral to intellectual growth. The movement is metaphorized linearly, but it involves detours, strategies, changes.

5. Community is task oriented.

a. From a foregrounded article presented as a course reading: IIn a discourse community]: "there is some common, public goal the group seeks to accomplish, some work the participants are trying to perform together... The group uses its forum to work toward its goal by providing information and feedback"

b. From a class log written by a student leader: "Noticing that the course ends November 3 may have heightened the intention of the group to orient quickly to the task at hand"

Comment: Class participants clearly see themselves as task oriented. Although there is no evidence here, they (unlike Katherine) perhaps see social activity as an integral part of intellectual activity.

6. Community sits; it does not stand.

a. From a student log: "The grading session with Cathy and Carol was really great today. We really read into the papers and got a lot of insights. It was fun sitting around on the floor and just talking. The teachers in this class are so open and interested in our opinions is so beneficial not only in writing [sic], but in the attitudes that I have about this class"

b. From a student journal: "Are we above this? Obviously not. We spent 90 minutes debating this point today - to the effect of apathy among everyone except those people with a major issue to raise with their critics. Everyone left in a bad mood today, and this is only going to escalate."

Comment: One participant values the community for its comfortable interactional behavior. Using spatial (vertical) metaphors, the other participant expresses distress when arguments arise in the classroom. Escalation, raising, "up" is negative; sitting, reading into, "down" is positive (cf. community is horizontal, not vertical). In real community, participants are at ease: sitting and talking. Chaos in community is rising in debate.

\section{Intertextual Thematic Formations}

In order to analyze more closely how Katherine's language can be seen as forming sometimes conflictive intertextual ties with the language of the classroom, I focus on the first condition distilled from her lexical metaphors: Community is not dramaturgical.

Katherine's recurrent instantiations of this metaphor realize their meaning from a text built up during the course of the semester as well as her own historical understanding of community. However, because the community metaphor was presented as subject matter and as favored lens for understanding the activities of the classroom, the conditions for interpreting the community metaphor and vari- 
ous instantiations of it were quickly formulated in the classroom. In fact, some basic conditions for understanding the community metaphor were presented within the first moments of the first meeting in the first paragraph of the course syllabus which read:

\section{Text 5}

This composition course is designed to initiate conversation about reading and writing as social acts. We will analyze the personal implications of the fact that the meaning of literacy is always shaped by communities which develop guidelines and principles for the making of meaning. Becoming a fully participating member of a new community (for example, the engineering community, the sports medicine community, the comparative literature community, and so forth . . . ) means learning "appropriate" ways of doing, speaking, and writing. It finally must also mean learning to negotiate the limitations of a community's guidelines and rules.

Among the various social voices, which together constitute this introductory statement to students, there are two discourses that were destined to become critical to the ways in which students thought and spoke and wrote about community. These two discourses became part of a system of semantic relations between spoken and written texts designated as intertextual thematic formations (ITFs; Lemke, 1988). ${ }^{1}$

In this discussion, the term ITF will be used to identify a discourse defined by the thematicization of recurrent lexical metaphors. As rhetorical devices, recurrent metaphors function as phenomena of intertextuality. They form semantic ties across texts which are not obviously related by, for example, genre. Recurrent semantic relations or ITFs regularly construed within or across texts, in part, define a community; that is, a community can be characterized by the way it chooses to juxtapose the various social voices that constitute all language. When the juxtapositions of social voices become regularized (when they become part of a system of ITFs), they link texts which speak about the same subject or texts which constitute the social activities of communities. It is against the background of this system of ITFs that individual instances of student and teacher language become meaningful. In Text 5, one discourse or ITF will be called /DRAMA/ and where it applies to the activity of community building, it will be called /DRAMA:C/. The other critical discourse will be called/ETHICs/ and where it applies to the activity of this community will be called/ETHICs:C/.

The discourse /DRAMA:C/ is more or less partitioned throughout the introduc-

\footnotetext{
${ }^{1}$ Although I rely heavily on the work of Lemke in this discussion of intertextuality, it should be noted that Lemke uses very precise thematic-semantic relationships to define ITFs. These relationships include the categories of systemic-functional grammar and lexical cohesion analysis (see. especially, Lemke, 1988, pp. 41-48). In this discussion, I provide brief glosses of ITFs without analyzing thematic-semantic relationships. Hence, an ITF in this discussion is more akin to a field of discourse; however, it is defined by thematicizing recurrent lexical metaphors
} 
tory statement in these phrases: reading and writing as social acts; guidelines and principles for the making of meaning; successfully learning; "appropriate" ways of doing and speaking and writing. Recalling for a moment the ALTERNATE CONDITIONS, it can be seen that class participants are being invited to view activity in communities as involving the assumption of roles. They are being asked to consider the fact that communities have conventions for the making of meaning. In the language of literacy, this is the meaning of language acquisition and community-building; in the language of theater, this is the meaning of drama.

The discourse /ETHICs:C/ surfaces in these phrases: initiate conversation; "appropriate" as a token in "appropriate" ways of doing and speaking and writing; negotiate the limitations of a community's guidelines and rules. In these instances, students are being invited to view the classroom as the location of ethical behavior. Literacy learning means actively engaging in conversation rather than "passively" listening to lecture. It means shared understandings, negotiation, and consensus. Readers will recognize this type of liberal humanistic pedagogy currently valued in educational literature. It is a pedagogy based on humanistic values and ethics, carried out through the distribution of power in the classroom. At the same time, the conversations are to be governed by rules: There are rules for meaning-making in this community as in all communities. Yet learning roles and rules-appropriate behavior-is also governed by ethics: Sometimes rules must be resisted in the interest of critical thinking and value orientations.

The heteroglossic relationship between /DRAMA:C/ and /ETHICs:C/ is one of ALIGNMENT; that is, community is to be understood as defined or constituted, in part, by both of these discourses, and they are not in opposition to one another. In fact, this foregrounded relationship was an entry condition to the semiotic system of the classroom as constructed under the community metaphor. The teacher agenda was such that activities were designed to get the students to see a dialectical relationship between conventions of discourse communities and resistance to conventions of discourse communities.

Many, many texts were unfolded in this course that were directly linked to this heteroglossic relationship of ALIGNMENT. It was the major ITF of the community.

The individual texts of Katherine, her peer group, other students, and the teachers were construed in relationship to this ITF and took their meaning from it, that is, all texts were composed of choices-in-context. The choices and subsequent relationship were either HOMOLOGOUS or CONTRASTIVE. Inasmuch as the community metaphor was imposed by the teachers of this course, however, not all choices were equal. Thus, Katherine composes a text (Text 2) in which grammatical metaphor is played out between a HOMOLoGous relationship with the ITF and a CONTRASTIVE relationship with the ITF. And she situates herself within the HOMOLOGOUS relationship: The "appropriate" way of doing and speaking in this community. She positions her peers in the CONTRASTIVE rela- 
tionship. This may very well have been the way that it was; regardless, in operationalizing these precise relationships, Katherine made them functional through a set of signifying practices with the teacher interviewer. These were the functional channels at that moment in time.

In many of Katherine's other texts, however, she creates and positions herself within channels which are not in Homologous relationship with the dominant ITF. In fact, the lexical metaphors of her texts are distilled into Condition 1: Community is not dramaturgical, which appears to be in direct opposition to /DRAMA:C/. It is as if she bypasses the entry condition to the community. The explanation for this is perhaps twofold. First of all, Katherine arrives in the community unfolding texts in relationship to the discourses /DRAMA/ and /ETHICS/ which only intersect and do not converge with / DRAMA:C/ and/ETHICs:C/. She draws from her own historical text, a text that differs from the community text. Second, in the event that only part of an ITF is operationalized, the semantic relationship of ALIGNMENT need not hold for meaning to take place, that is, thematic contrast as heteroglossic relations surface. Thus, as long as /ETHICs:C/ does not appear to surface as a discourse, Katherine can meaningfully OPPOSE /DRAMA:C/ which she in fact does repeatedly, as demonstrated by Condition 1 . These two situations cause difficulties for her in the community. Both figure into the following cpisode:

\section{Text 6}

C: Do you go out of your way not to offend them [classmates] or do you care if you offend people/ or does it [sic|'?

$\mathrm{K}$ : Yeah sometimes I try to hold back/I could be really/ you know/tell people what I really think but /you know/sometimes I let it out like that one day that guy/ I don't know his name/ he always kept talking so much and proposing things to vote on and it was too much/ so 1 told him to be quiet and he got mad/ what was his name?

C: Alex?/ the one with the blonde hair and glasses?

$\mathrm{K}$ : yeah

C: tell me about that

K: that?/ well see/ there's/I don't know/I don't know/I thought he was/I just had a bad idea about him/ he ended up being nice and all but in the class when he would talk and stuff it would just aggravate me/ the way he would talk

C: why?

$\mathrm{K}$ : I don't know/ something about him/ he/ I think he tried to use big words and they just wouldn't come naturally or something/ but they didn't/ like you know/ people with good vocabularies talk to you/but he would just sit there and try to bring the words out or something/I don't know.

Rather embarrassed in her recounting of this episode, Katherine weaves the /ETHICS:C/ discourse to the /DRAMA:C/ discourse in the interview: Alex was nice after all, but in the act of community building, he stages a drama that Katherine cannot abide. Though she retrospectively creates an /ETHICs:C/ for Alex in the 
interview, in the real time of the episode she does not hear /ETHICS:C/ in his class talk. In the real time of the episode, there is no reason for ALIGNMENT:/ETHICS:C/-/DRAMA:C/. It is only some time after this episode in class, when Katherine establishes a friendly relationship with Alex in a one-to-one encounter that she can retrospectively figure an /ETHICs:c/. Thus, she feels embarrassed in recounting the episode to the teacher interviewer. She should not have felt so embarrassed because the episode was further complicated and can, in part, be explained by her own historical text. I would like to suggest that the initial episode - her exchange with Alex in the whole-class conversation-was affected by a formation /DRAMA/ and /ETHICS/ that is manifest in the following exchange in which she describes activities of her father:

\section{Text 7}

C: so his friends are his old established friends just like you here [at the university]/ right?

K: yeah/I don't think he's made a friend besides the people who work for him/ but with them/ he doesn't want to become close to them/ he'll keep it separate from work/ so he's never made any outside friends I don't think/ he knows a lot of people

Katherine has her own ideas about community. In her family, there's a difference in the way that /DRAMA/ positions itself in relationship to /ETHICS/. She describes what she perceives a strong Iranian-Macedonian world view in her family and, here, the world of work is separated from the implicit drama of community building. This is an /ETHICS:F/, a family ethics in which it is natural to her that "he [her father] can set up/ like where/ a boundary." This is as ethical to her as the world view of, for example, the teachers of the course who saw the work of community building as always ALIGNED to a discourse /ETHICs:C/. During the semester, Alex was perceived by the teachers as a "model" student in the community: He was forever trying to negotiate a consensus, a common language among the diverse voices in the classroom. Inside the dominant classroom ITF, Katherine's /ETHICS:F/ seem to interfere. It pushes against /ETHICS:C/ at a point of opposition. The dominant ITF was so strong that Katherine never knew that the /ETHICS:F/ of the episode of Text 6 , which caused excruciating silence sprinkled with embarrassed laughter in the classroom that day, was actually in ALIGNMENT with another student's historical text. Ann, another student, sat silently championing belligerent Katherine for ethical reasons of her own.

Katherine in not unique in her linguistic complexity. What makes classroom talk so exceedingly complex is that all participants locate themselves in a multilevel, shifting network of signifying activity. This is the nature of language and meaning. This is the meaning of "language in context." The constant slippage between individual instantiations of language and the dominant ITFs of a community is what makes any language event meaningful. In this classroom, like in all situations of language use, all particular instances of language use are net- 
working with many ITFs in various heteroglossic relationships and simultaneously building or weakening the ITFs themselves. What made Katherine's situation unique was the limited number of "acceptable" functional channels available to her and the weakness of the relations construed within those channels. She simply found herself constituting a pattern of social activity in which she was only able to deploy and have taken up and to receive and take up signs with a certain semiotic potential, that is, dominated-like all linguistic activity-by certain ITFs. She perhaps found herself within a limited system of relations: a classroom operating with a limited number of functional channels. It is not the case, however, that she did not send and receive signals. Alaine was a sign of success to Katherine: leader. Hanna was a sign of conventionality: follower. The teachers were signs of expertise: knowledge and support. And, as she construed it, Katherine was a sign of failure: outcast. She just didn't connect.

As in Katherine's own texts, for every condition given, an instance of ALIGNMENT or OPPOSITION could also be found for other students and teachers or other occasions of use. As in all language use, ITFs clash and collide. Relations are strengthened or weakened. This is the nature of meaning. Unfortunately for Katherine, the favored networks of relations in the classroom which she intersected were too few, and the relations construed within those networks were too weak.

To designate Katherine as a resister, however, reduces the complexity of semiotic systems to an extreme. It limits her discourse or the discourse of students like her to oppositional relationships and delegitimates other relationships construed such as those in ALTERNATE CONDITIONS 4, 5, and 6. It oversimplifies the shifting, multiple levels of semiotic activity we call "language." On the other hand, to think of Katherine as a resister reduces the situation to a manageable level. For those who wish to call forth common languages and harmonious communities, chaos is neutralized. It is rendered insignificant by seeing it as contained within the localized interactions of certain students. Chaos can be dismissed. Ironically, when classroom participants ignore the chaos, the casualties are high. The irony involved in this particular situation and this particular community is that the casualties were never meant to be. In part, the point of aligning /DRAMA:C/ to /ETHICS:C/ was to circumvent the possibility of casualties at all. The pragmatist might offer consolation in the form of the commonsensical notion that every classroom inevitably has its casualties and, thus, the best the teacher can do is to try to limit the number. Yet such a notion could be seen in semiotics as another manifestation of "dynamic metastability" and, thus, it begs the question. If there were but other worlds.

\section{PART III: THE CLASSROOM AS COLLECTIVITY}

The flux of aligning and colliding discourses that characterizes language-inuse- - one constant in school talk-begs for consideration as we conceptualize. 
classrooms. Despite a mounting, insistent critique in educational literature of its reductionist nature, however, the community metaphor continues to be attractive to teachers. One reason for the reluctance to give way in the face of either empirical evidence or critical discourse is that, properly managed, the notion of community allows for the unfolding of an ethical discourse in the shape of questions such as

- What is the relationship of the individual to the community?

- How are criteria determined for the shaping of meaning in communities?

- What does "critical thinking" mean when the rules for the shaping of discourse are determined if even by the community itself?

- How are disjunctions maintained and why?

To conceptualize the classroom as a community allows space for an ethical discourse in the hopes that it will reverberate throughout the many discourses outside the classroom.

Such a project, unfortunately, remains inexorably idealistic. Inside and outside the classroom, the parameters even of "ethical" discourse are shaped by those with the position or courage or power to prevail over ethical matters as they arise out of classroom and real world discourse. Ethical discourse, like all discourse, is shaped by political considerations. To christen one's group as community - if even in search of an ethical discourse-masks the fact. There is no common language, even in the realm of ethics, if, in using the notion, we mean to neutralize the inherent violence in language in the interest of seeking the consensus: the lowest common denominator. By distancing itself from the thoroughly heteroglossic dimension of language in its search for a unifying ethical discourse, the community metaphor ends up defeating its own purpose. Within the political confines of the institutional setting of the university, and within the temporal confines of a writing course, genuine community most often may not be humanly possible.

Lest this sound all too cynical, we ought to consider what this phenomenon-community-is in itself. What, after all, is this community that we believe we can built into our curriculums? Certainly, it is not just a local manifestation. Genuine community entails a spiritual dimension that, perhaps, defies all languaging. It traverses temporal and spatial dimensions. It slips through our pedagogies and methodologies as it flickers on and off again among two or more ontological human beings. It is tangential to our plans and intentions, arriving imperceptibly, through a kind of grace we cannot build into curriculums. It is certainly not the norm in the classroom or in the disciplines so lightly christened "communities," yet so fraught with violence as Ohmann (1976) and Bennett (1989), among others, have pointed out.

As we use the term, however, we turn community into a commodity: something to be had along with the grades distributed throughout our courses, or 
something to be had along with the buildings that house the groups of scholars with shared academic interests. We concretize it and stabilize it. We make it static. And by doing so, we ignore the tension inherent in the very dynamics of language and the dynamism demanded of the continuous action and reflection, action and reflection, of genuine praxis. In view of the contradictions implicit in even the ethical dimension of the notion of community, we must relinquish the idealism and the reductionism.

This is not at all to say that we should not engage in utopian imaginings. As teachers in the humanities, as human beings who would seek to release the future from its bondage in the gross inequities and injustices of the present day (i.e., injustices which keep human beings from reaching their full potential), we must foster a discourse of liberation; even as it cuts into the fabric of our first world students' comfortable and oftentimes egotistical lives. At the same time, we must avoid euphemism. We must realize that the liberation we seek will forever remain partial and incomplete, never absolute. Our classes, our marginalized students, and all our first-world students-as they help constitute a dominant imperialist ideology resulting in the negation of the emancipation of others-for example, the third world-demand daily liberation. This is a project that calls for other than euphemism. It demands honesty, self-criticism, and the ability to confront contradictions that prevent a human solidarity which is itself constructed on the constantly changing foundations of human praxis.

\section{Collectivity: New Metaphor, New Meaning}

One way to begin to grapple with the contradictions, as I suggested earlier, is to conceptualize the classroom as a collectivity. First of all, and most crucially, this is not simply a matter of replacing one imposed metaphor with another. Metaphors, as I will shortly discuss, can and do arise spontaneously in the normal functioning of groups in process. To proceed initially from a collectivity metaphor, however, is to proceed from a helpful framework that more adequately captures the real dynamics of language-in-use.

To illustrate this point, I suggest consideration of the senses typically identified with the two terms. Whereas the semantic content of the word community calls forth senses such as "commonness, agreement, identity, and fellowship," the semantics of the word collective calls forth senses such as "constituting a collection; gathered into one" (OED). The latter senses more aptly describe the composition classroom where students are most often gathered together involuntarily, to fulfill university requirements. If there is any sense in which a composition classroom finds "agreement," it is in the sense that students simply want and need to fulfill university requirements. By avoiding the idealistic senses evoked by the world community and by calling forth senses of proximity and pragmatics, the word collectivity offers the randomness necessary to capture the dynamic flux - the alignments and collisions-of discourse-in-use. It can capture the functional nature of discourse and classroom groups: temporary arrangements in 
which students have multiple intentions, motivations, and goals. Divested of romantic or idealistic visions of classroom and academic life, students and teachers are called to see that, outside the feelings of fellowship they may experience from the sympathetic, chance, dialogic intersections, the rule of discourse is that it is normally conflictual.

A classroom divested of idealistic notions about life in social groups is not a classroom divested of emancipatory potential. I would like to suggest that the term collectivity has greater potential to foster a genuine ethical, liberatory discourse. It begins with diversity. The solidarity it seeks to locate, both as a semantic feature and a social reality, begins from the bottom up. This is in opposition to the top down focus of community. The solidarity it seeks to complete itself as a human construct is a new kind of solidarity: cognizant of struggle and conflict, and constituted of difference and dynamism.

Some thoughtful teachers, however, may still see difficulties with the term collectivity for semantic reasons. One criticism of the term I have often encountered is that the word carries undesirable historical-political meanings. The term evokes negative images of, for example, enforced collectivization. To this criticism, my response is this: exactly right. I see the historical freight of the term collectivity as an advantage because it allows for a foregrounding of the political nature of groups and language in groups. The term foregrounds exactly what the term community makes invisible. Teachers can use objections to the term as a means to open a discussion about the politics of language. This can be discussed without the moral/spiritual constraints set forth by the word community. To illustrate, I personally found it difficult to initiate a criticism of the community metaphor because I initially felt constrained by ethical considerations. We all cherish the communion we feel with family, friends, and students. Who wants to disparage it? I suggest students feel the same: This may be part of the reason why Katherine defined herself as an outcast. She saw herself as outside the sanctioned unity of the group. She assimilated the guilt of her inability to find communion, not recognizing that the problem was systemically related to the politics of language as defined by the community metaphor. When communion becomes an expectation, it becomes mystifying rather than mystical.

With a clearer understanding that language and language practices involve a radical dynamism - the inherent violence of colliding discourses-students are perhaps more apt to look pragmatically at their status both in the classroom and in the university where they are struggling to gain entrance to disciplines and professions. The truth is that one cannot always enter any linguistic group through sheer desire and the ability to mimic a discourse. And, to broaden the discussion, they are also more apt to see that critical thinking alone, that type of higher-order literacy we try to nurture in our students, is not enough to create new worlds. Only when individual discourses gain momentum and strength from aligning with other discourses will change occur in their disciplines and beyond. They may see that ushering in the future is not the project of the individual, but of 
a collective which, in turn, aligns with other collectives for the duration of a common project. The sense of identity construed from this view of collective relationship is one of an elastic solidarity created through the preference ${ }^{2}$ of human beings, who are subjects rather than objects, in an emancipatory process.

A new, more humane world demands flexibility and acceptance if it is to avoid the absolutizing of truths as so frequently happens in groups which see themselves as stable, enduring, absolute communities.

The stance of the teacher in the collectivity is, in part, one of ready, active watchfulness: reflection and action in response to the signs traversing the situational context. The teacher may be sensitive to "zones of proximal development" for student growth. The teacher can nurture critical thinking, deeper understandings of the political nature of all discourse, more humane conceptualizations of history, reevaluations of the dignity of the voiceless and disempowered. An ethical teacher will create space for the possibility of richer, more diverse, more numerous intersections. But the teacher cannot either impose an artificial solidarity or change the violence inherent in social discourse. Rather, the teacher works with the violence: drawing attention to it, and harnessing the restlessness it creates in concerned human beings, in the interest of dismantling the social apparatuses that would seek to diffuse and deny interpersonal, social, and structural violence that can be evidenced, in part, in linguistic formations.

\section{Collectivities-in-Process: Student-Generated Metaphors}

With this basic, realistic understanding of linguistic and social reality, teachers then might help students see how they define themselves as a group-in-process. As Srivastva and Barrett (1988) pointed out, groups naturally will develop metaphors to capture facets of their understanding of their social relationships. The metaphors will shift and change as the group experiences the dynamism of their own growth and cohesiveness. Student-generated metaphors may help facilitate new understandings for individuals and the group as a whole. Poised in watchfulness, the teacher would listen to class conversation for consciously and unconsciously constructed metaphors in order to help students see how they are constructing their own social reality. In part, the teacher's goal, based on and sensitive to students' own conceptions of their social reality, would be to facilitate new intersections, new concepts, new "zones of proximal development" in the interest of encouraging new, critical action derived from new intersections. And, of course, as part of the conversation, the teacher would also be part of the

\footnotetext{
2The term "preferential solidarity" is used by, among others, liberation theologians in their search to name the concerted effort to build social justice in a world flawed by politically sanctioned structural violence (see Baum, 1989). Although appropriating this term, I nevertheless mean to maintain a recognition of the inherent existence of violence in linguistic practices. Such a vicw would be, perhaps, less consistent with Baum's view than with the view of other theologians, such as Segundo (1976).
} 
learning, sharing, growing. Teachers and students would learn from naming their own world, as diverse and "messy" as that will be.

Last year, I began to invite my students to conceptualize our group as a collectivity. The new metaphor was presented in the course syllabus and I used the metaphor in my own contributions to classroom conversations. I also began to listen for student-generated metaphors. I asked students to describe the group during the third session of one of my composition classes. They offered these metaphors:

1. A group of kids newly adopted by our mother: each of us different. No relation.

2. Actors waiting to perform a new script

3. My mother's cooking: a pinch of this, a pinch of that. Each member is one of the spices.

4. An ice cream parlor with 16 different flavors

5. The United Nations

6. A trip to the dentist when you know you have cavities

7. A cross-section of society

8. A group therapy session

9. A highway system: the streets cross in different places and this is where we meet. Each street will continue onward out of sight, but each of us meet in the intersection.

10. Our class is like a fishbowl. In it we have diversity as well as similarity. We have a warm supportive place to grow. We have a caring owner who monitors this, but does not get overinvolved, allowing us to keep our liberty. We have peers who are compassionate, but firm enough to nip our tails when we get out of line.

11. This class is like a multifaceted prism. Every angle gives off a different color light for all to see and reflect upon.

These metaphors, though consciously constructed and shaped by rhetorical considerations, reveal crucial aspects of my students' diverse conceptions of their own context-of-situation. Some are encouraging; others call for concern. Several capture the dynamism of a collectivity and language in a collectivity. Most demonstrate that students view the collectivity, not as a monolithic structure, but as a location where diversity is recognized: indeed, where diversity is constitutive and not simply allowed. As the classroom conversation continues to unfold throughout the semester, students will continue to pose new metaphors that reflect their sense of achievements and failures, of their cohesiveness and incapacities to cohere. And I will attend to these metaphors, seeking to facilitate new intersections: mindful that, although the individual can be victimized by the system as a whole, the individual, as an individual, cannot effect change in the system alone. Thus, in addition to reflecting on these metaphors and asking my students to reflect on them as well, my goal will be to encourage active, elastic 
solidarity governed by the embracing of difference as necessary, normal, and valuable and by the embracing of social justice--inside and outside our small university world-as the guiding principle for preferential solidarity. Consequently, I would hope that as my students realize the tension inevitable in all language, relations, and structures, they may find reason to engage in more realistic strategies to cope with it: one of which may be the devising of goaloriented coalitions of human beings struggling for significant social change.

\section{REFERENCES}

Bakhtin, M.M. (1981). The dialogic imagination. Austin: University of Texas Press.

Bakhtin. M.M. (1984). Problems of Dostoevsky's poetics (C. Emerson, Trans.). Minneapolis: University of Minnesota Press.

Bakhtin, M.M. (1986). Speech genres and other late essays (V.W. McGee, Trans.). Austin: University of Texas Press.

Baum, G. (1989). Community and identity. In M.H. Wllis \& O. Maduro (Eds.). The future of liberation theology (pp. 220-228). Maryknoll, NY: Orbis.

Bennett, J.R. (1989). National power and objectivity in the classroom. College English, 5I. 805824.

Clark, K., \& Holquist, M. (1984). Mikhail Bakhtin. Cambridge, MA: Belknap.

Eco, U. (1984). Semiotics and the philosophy of language. Bloomington: Indiana University Press.

Geertz, C. (1988). Works and lives. Stanford: Stanford University Press.

Giroux, H.A. (1981). Ideology, culture, and the process of schooling. Philadelphia: Temple University Press.

Giroux, H.A. (1988). Teachers as intellectuals. Granby, MA: Bergin \& Garvcy.

Giroux, H.A., \& Aronowitz, S. (1985). Educalion under seige. South Hadley, MA: Bergin \& Garvey.

Goffman, E. (1959). The presentation of self in everyday life. New York: Anchor.

Goffman, E. (1967). Interaction ritual. New York: Pantheon

Goffman, E. (1971). Relations in public. New York: Harper.

Greene, M. (1978). Landscapes of learning. New York: Teachers College Press.

Halliday, M.A.K. (1985). An introduction to functional grammar. London: Edward Arnold.

Harris, J. (1989). The idea of community in the study of writing. College Composition and Communication, 40, 11-22.

Lemke, J. (1983). Thematic analysis: Systems, structures, and strategies. Recherches Semiotiques, 3. 159-187.

Lemke, J. (1984). Textual politics: Heteroglossia, discourse analysis, and social dynamics. Paper presented at the International Summer Institute for Semiotic and Structural Studies. Toronto.

Lemke, J. (1988). Discourses in conflict: Heteroglossia and text semantics. In J.D. Benson \& W.S. Greaves (Eds.). Functional perspectives on discourse (pp. 29-50). Norwood, NJ: Ablex.

Morson. G.S. (Ed.). (1986). Bakhtin. Chicago: University of Chicago Press.

Ohmann, R. (1976). English in America: A radical view of the profession. New York: Oxford University Press.

Ortony, A. (1979). Metaphor and thought. New York: Cambridge University Press.

Petrie, H.G. (1979). Metaphor and learning. In A. Ortony (Ed.), Metaphor and thought (pp. 438461). New York: Cambridge University Press.

Segundo, J.L. (1976). The liberation of theology (J. Drury, Trans.). Maryknoll, NY: Orbis.

Srivastva, S., \& Barrett, F.J. (1988). The transforming nature of metaphors in group development: A study in group theory. Human Relations 41 . $31-64$. 
Stock, P., \& Robinson, J. (1990). Literacy as conversation. In J. Robinson (Ed.), Conversations on the written word (pp. 163-238). Portsmith, NH: Boynton/Cook; Heinemann.

Todorov, T. (1984). Mikhail Bakhtin: The dialogic principle (W. Godzich, Trans.). Minneapolis: University of Minnesota Press.

Willis, P. (1977). Learning to labor. New York: Columbia University Press.

Winkelmann, C. (1990). Talk as text: Students on the margins. In J. Robinson (Ed.), Conversations on the written word (pp. 115-128). Portsmith, NH: Boynton/Cook; Heinemann.

Zaliznjak, A.A., Ivanov, V. V., \& Toporov, V. N. (1988). Structural-typological study of semiotic modeling systems. In D.P. Lucid (Ed.), Soviet semiotics (pp. 47-58). Baltimore: Johns Hopkins Universily Press. 